
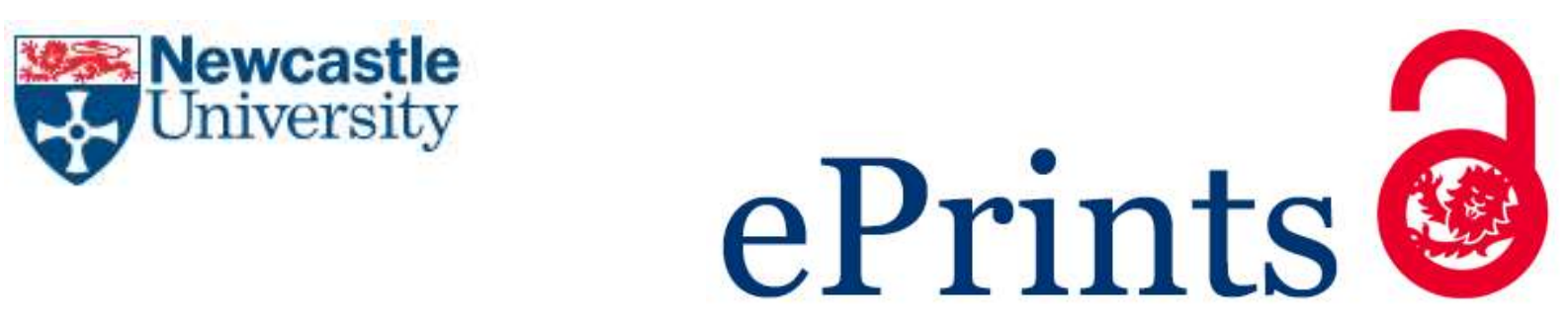

Jarvis H. Sharing, Togetherness and Intentional Degrowth. Progress in Human Geography 2017

\title{
Copyright:
}

This is the authors' accepted manuscript of an article that has been published in its final definitive form by Sage Publications Ltd., 2017

DOI link to article:

https://doi.org/10.1177/0309132517746519

Date deposited:

$19 / 12 / 2017$

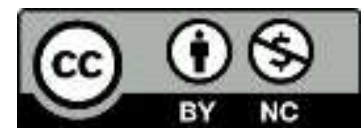

This work is licensed under a Creative Commons Attribution-NonCommercial 3.0 Unported License 
Jarvis (2017) Sharing, Togetherness and Intentional Degrowth. Progress in Human Geography (in press).

Helen Jarvis

School of Geography, Politics and Sociology

Newcastle University

Helen.jarvis@ncl.ac.uk

\begin{abstract}
This article proposes a social phenomenology of intentional sharing and togetherness from a degrowth perspective: extending human relations instead of market relations; deepening democracy; defending ecosystems; and realising a more equal global distribution of wealth. Social phenomenology looks beyond individual mutual exchange to the rich but fragile social construction of collectively negotiated ethical purpose. Intentional communities of cohousing are identified as part of a solution to dismantle privatised, conspicuous consumption. This approach challenges the tendency in popular sharing economy discourse to conflate different types of togetherness, highlighting instead the social significance of skilful cooperation and conviviality in groups and associations.
\end{abstract}




\section{Sharing, Togetherness and Intentional Degrowth}

\section{Introduction}

This article proposes a social phenomenology of sharing and togetherness, elucidated in a two-fold argument. First, it advances well-established human geography debates on the socalled 'sharing economy' and the wider notion of 'sharing cities' (Agyeman et al., 2013; McLaren and Agyeman, 2015; Sundararajan, 2016). This body of work draws together intersecting theory and evidence of diverse marketplaces and smart, digital technologies that enable people to buy, share and rent goods and services in 'circular economies' of 'collaborative consumption' (Hobson, 2016). Arguably, the advent of new technologies has reinvented the language and meaning of 'sharing' in dubious ways. This is made apparent when social phenomena of collective and purposeful sharing are distinguished from consumption-oriented, aggregated, individual economic transactions and efficiencies. To counter the persistent individualism in sharing economy discourse, inspiration is drawn here from anthropological studies of voluntary association and cooperation, to shine a light on joint action in groups of collectively negotiated subjectivity (Price, 1975; Belk, 2014; John, 2016; Sennett, 2012; Hemmings, 2011).

Second, this article draws on degrowth thinking to advance the transformative potential of joint action in groups. Degrowth thinking is beginning to emerge in the English-language human geography literature (Kallis and March, 2015; notably Krueger et al., 2017), but it lags French and German conference proceedings on the subject (D'Alisa et al., 2015: xxiii). Moreover, the English-language debate is characterised by origins in ecological economics (Princen, 2005; Jackson, 2009), offering limited appreciation of the social structures, skills and learning entailed when groups of citizens organise to practice degrowth (Muraca and Schmelzer, 2017). Thus, connections have yet to be made between degrowth theory and actually existing communities of intentional sharing. In short, a two-fold argument is necessary to challenge the extent to which sharing economies reinforce unsustainable and unjust economic growth, by emphasising individual consumption instead of collective meaning and action. These challenges call for the social functions of sharing and togetherness to be reconceptualised in micro-social organising against cultural norms, such as hyper-individual dwelling and conspicuous consumption (Lietaert, 2010: 580). 
Throughout the discussion, concepts of sharing and togetherness are illustrated with reference to self-organised 'housing-cum-neighbourhood' schemes known as cohousing. The defining features of cohousing include the clustering of smaller-than-average private homes, which may be owned or rented, with extensive shared outdoor space and common facilities for shared daily use. Cohousing is broadly defined as an intentional community whereby residents actively participate in the design, planning and governance of their neighbourhood as a whole. Mattheiu Lietaert (2010: 577) identifies cohousing as 'part of the solution' to dismantle privatised and conspicuous consumption because 'being largely an urban phenomenon' cohousing communities demonstrate a 'constructive alternative to the growing atomisation and loneliness of individuals in large cities' (see also Doherty and Etzioni, 2003). As Ludwig (2017: 13) observes, 'every intentional community is experimental to some extent......attempting something cooperative within the context of a highly competitive culture'. Cohousing is just one example of intentional socio-spatial sharing which could serve the argument of this article just as well. Indeed, it must be stressed that cohousing is referred to for illustration rather than as the substantive focus of analysis.

The structure of this article is in four parts. The first part outlines the multiple and contested meaning of sharing resulting from new platforms and applications of digital technology. This 'mosaic' exposes inevitable complexity and the hazards of reinforcing simplistic binary distinctions between virtual and material sharing practices (Richardson, 2015). It highlights a continuum of old, new and reinvented networks of solidarity, including opposition to the standardising effects of globalisation. Research to date has drawn attention to resource sharing within virtual communities (such as Freecycle) (Nelson et al., 2007), and for specific populations of students and young professionals (Heath and Kenyon, 2001) - but little has been published on situations where sharing and togetherness are intentional and enduring, by groups imagining and realising novel forms of cohabitation.

Countering the individualistic principles of classical phenomenology, the second part advances an explicitly social phenomenology, using this to look beyond individual transactions of mutual exchange to the social construction and embeddedness of collectively negotiated group subjectivities, intentional 'we' thinking and ethical purpose. The third part introduces intersecting ambitions of degrowth to demonstrate how this 
interdisciplinary body of theory reclaims a social and political purpose that is necessary if debates on sharing are to 'escape' the economy. The fourth part applies this combined approach as a lens through which to differentiate three 'ideal types' of togetherness- 'living togetherness', 'thrown togetherness' and 'intentional togetherness,' that tend to be conflated as unproblematic sharing scenarios in current debate. Comparison further underscores the opening argument that current emphasis on sharing economies conceal social functions of convivial association and ethical purpose that are essential to social organising against consumer treadmills of neoliberal growth. This way, anthropologist Russell Belk (2010: 715) argues that the word 'sharing' is used as if it were a 'fundamental consumer behaviour'. A degrowth perspective tackles this consumption-bias by dismantling economic growth as the central organising principle of social life (D'Alisa et al., 2015).

\section{Multiple and contested meanings of sharing: the sharing mosaic}

As an 'evolutionary trait' of human behaviour, 'sharing' is common to all cultures across the globe (Schmidt and Sommerville, 2011). The etymology of this term, from the Old English scearu (cutting, division) and Germanic schar (troop, multitude), reveals a variety of meanings that coalesce in the phenomenon of propinquity: gathering in groups and public places; joint use of resources; apportioning or allocating goods, services, stories, labour and land; enjoying or suffering experiences in common with others; confessing or disclosing a state of mind. In his book, The Age of Sharing, Nicholas John addresses the etymology of this word and the place it has taken in our lives, including how corporations are capitalizing on the positive 'sharing is caring' connotations that the word has come to evoke since the 1970s (John, 2016: 3).

Current debate refers to sharing as a transactional practice, used in popular discourse as a proxy for social connection. Yet, as a means of connecting people to things or each other, sharing can be 'real', or virtual, rivalrous or non-rivalrous, simultaneous or sequential, intentional or serendipitous. Sharing is variously associated with things, services and experiences- helping people to share access to assets, resources, time and skills (Richardson, 2015: 122). These can be the objects of consumption (e.g. digital music files to download) or production (e.g. community gardens) or of re-production (as with shared endeavours of DIY home improvement and co-parenting). Transactions can be for-profit or not- whether 
swapping, gifting or raising funds for a good cause. Indeed, goods can be identified on a continuum of rivalry, depending on the extent to which consumption by one consumer prevents simultaneous consumption by another. In general terms, almost all private goods are rivalrous and there are persistent tensions between private interests and the shared public realm. An example of simultaneous sharing would be open access to a public park (enjoyment is dependent on being in the park there and then) whereas goods that are recycled between one use/person and another demonstrate sequential sharing. Through sequential sharing, an increasing range of goods assume multiple purposes and 'after lives' via gifting, swapping, selling on, recycling and storage (Crang et al., 2013; Hobson, 2016: 96).

While elements of shared space, social interaction, and the joint use of resources are widespread, the motivations and consequences of these propensities are not universal. In general, individualistic cultures appear to value things, while collective ones emphasise relationships (Gabriel, 2013). Sharing is strongly influenced by geographically uneven cultural learning- and by local social norms and legal codes of privacy and property (Belk, 2014). For example, neoliberal market economies, notably in the UK, USA and Australia, typically sponsor a dominant housing regime (owner occupation) that locks the respective society into a homogenous material culture that inhibits sharing. This coincides with negative consequences for the planet, including extraordinarily high carbon emissions and energy consumption associated with conventional single-family dwelling. This has led degrowth commentators, such as Harvey Molotch (2003), to observe that one solution to the problem of people buying excess 'stuff', and then facing the problem of how to reuse or recycle the stuff that is not needed, would be to promote more collective, cooperative living arrangements (Jarvis, 2011).

\section{The 'Social Web' of Sharing Economies}

Since 1992, all aspects of daily life have arguably been transformed, first with the internet and Web 1.0 communication, notably e-mail, and more recently the 'social web' of Web 2.0 social media digital tools and platforms, allowing users to contribute content, connect with each other, and to share access to each other's underutilised assets, including their homes, on a short-term basis (Martin, 2015: 149). It is in the context of social media that the language of sharing has proliferated in misleading ways. As John (2017: 85) observes, 'since 
its inception, the internet has been culturally and discursively associated with collaboration, cooperation, connectivity and community. For example, peer-to-peer (P2P) platforms connect various members to one another directly, without a permission-granting intermediary'. Yet, 'the term peer-to-peer refers to computer networks, and to use it in relation to networks of people is to use it metaphorically' (John, 2017: 85). The same can be said of the 'sociality' of the 'social web' where collaborations are atomistic, economistic and consumption-led (Maniates, 2001). Critics observe that the relative anonymity of P2P connections characterize new practices and articulations of online 'sharing' as 'pseudosharing' or as 'commodity exchanges wrapped in a vocabulary of sharing' (Belk, 2014: 7).

In 2010 Rachel Botsman coined the term 'collaborative consumption', used interchangeably with sharing, to celebrate multiple new ways to 'connect things that aren't being used, with people who could use them' and as a 'radically better way of achieving higher utilisation (and profit) of capital's idling capacity' (Schiffere, 2013). There has since been a tendency to use this term uncritically, suggesting that exploiting 'idling capacity' contributes to a 'circular economy' that is sustainable or carbon-neutral. In the ideal circular economy, resources are kept in use for as long as possible, extracting maximum value by recycling the products or renting them out to multiple users at intervals when previously, in a linear economy, they would have been thrown away at the end of individually specified usefulness. In practice, the most high-profile brands of collaborative consumption rarely get close to the resource efficiency and zero waste of a true circular economy (Hobson, 2016).

Innovations in digital platforms and applications have undeniably 'ushered in a new era of sharing', with countless new entrants participating in 'crowd-based capitalism' (Belk, 2010; 2014; Sundararajan, 2016: 26). The 'social web' of the 'sharing economy' and 'collaborative consumption' are variously credited with creating a 'democracy of buyers and sellers' and a 'locust economy' (Brown and Morgan, 2006; Rossa, 2015) peddling the 'pure neoliberal ideology (that) if you have any spare resources and you are not monetizing them, then do not complain about being poor' (John, 2017: 69). Especially controversial are the ways that social media applications exploit the 'free labour' of users and visitors: Airbnb is an example of this, where proliferation of user interactivity include innovations in peer-review rating systems (such as Trip Advisor) that rely on trust and security between strangers. Critics point 
out that 'Airbnb is not a platform for sharing, but rather for short-term renting' (John, 2017: 69), at the same time undercutting more heavily regulated hotels, and reducing the supply of permanent affordable housing. Arguably, the so-called sharing economy frequently exploits social relations of trust and conviviality in ways that reinforce lifestyle practices that exacerbate social divisions based on private ownership, class, austerity and conspicuous consumption. Indeed, critics point out that persistent emphasis on reinforcing rather than limiting cycles of consumption shows that our lives have become commodified and increasingly mediated by the market- adding new, niche, 'alternative' markets (Seyfang, 2010) rather than cutting overall consumption.

\section{Real places and co-present realities}

Much as it is a stretch to regard collaborative consumption as holding the potential to bring about significant environmental benefits, as a true circular economy, it is equally problematic to think of the 'social web' as a social space in which to combat isolation and injustice. Yet, from the beginning, Web 2.0 applications consciously appropriated the language and imaginary of intimate, close-knit community relations and trust. This is especially apparent in 'hyper-local' P2P digital platforms which seek to recreate community 'proximity' and 'togetherness' by replicating the nostalgic idea of neighbourly interactions. A vivid example from San Francisco, globally recognised as a 'shareable city' hub (McLaren and Agyeman, 2015), is 'Peerby' which gets its name from 'Peer 2 Peer' combined with 'nearby'. According to their mission statement, Peerby is a small company with big ambitions that believes in the 'we' instead of the ' $\mathrm{l}$ ' (https://www.peerby.com/). Other application brands such as 'Share Some Sugar' and 'Hey Neighbor' similarly capitalise nostalgia for convivial streets and close personal circles (Jarvis and Bonnett, 2012).

In practice, real places and co-present realities of togetherness continue to exert a powerful influence on the 'sharing paradigm' and the potential to build 'a fair and sustainable world' (McLaren and Agyeman, 2015: 1). For example, most cohousing origin stories describe a lengthy period of group formation, steered by a core group of 'burning souls' as well as successive struggles for socio-spatial justice (Kanter, 1976). Phenomenology offers a humanistic theoretical framework within which to explore the process of group formation, to distinguish 'we' thinking and 'purposeful' sharing from 'pseudo' sharing in 'counterfeit' 
communities. The latter is problematic in the 'sharing cities' literature because the language of social connection can be cynically manipulated for commercial gain (Frei, 1998). This is evident in a new generation of co-living buildings such as The Collective, Old Oak in London, where all-inclusive rents and access to shared areas (games room, library, restaurant, bar and gym) and concierge services, function 'much like a hotel' to make it easier for young professionals to interact socially and feel connected (Ray, 2016). Residents in this 'counterfeit' community lack any self-organised or negotiated identity; united not by longterm needs or shared interests but a lack of alternative affordable housing.

\section{On the social phenomenology of sharing}

Corresponding with neglected understanding of the social, associational dimensions of sharing, the social development of phenomenology also remains underdeveloped. Phenomenology is defined as the interpretive study of human existence (Seamon, 2000: 3; Schutz, 1970). In its classical form, this approach draws attention to the construction of knowledge in human experience (values and attitudes), notably the emotional and sensory connections (real-world encounters) that shape human values concerning place and the natural environment (Tuan, 1974; Pickles, 1985). According to classical analysis, motivations and values are attached to an inherently introspective individual human subject. Critics point to an overemphasis on agency and individual experience that fails to account for relational processes of social-awareness and group interactions (Entrikin and Tepple, 2006). This way, learning is not limited to self-knowledge; rather, it reflects socially negotiated subjectivity.

By adopting an explicitly social phenomenology this article departs from the usual focus on the individual as an atomistic source of preference formation, to critically account for social situations of 'intentionality' (conscious learning from shared experience) (Jackson, 1981; Ash and Simpson, 2016). Social phenomenology invites closer and more critical consideration of collectively negotiated subjectivities and shared endeavours that shape and reflect shared knowledge (as with concern for, or denial of, anthropogenic climate change). This is a significant departure from conventional analysis of sharing, where higher utilisations (and profits) of the economy's 'idling capacity' are read off from individual transactions. 
With social phenomenology it is possible to focus on the micro-sociology of association, recognising that social encounters can be superficial or actively performed for conscientious listening and social learning (Bakhtin, 1986). It usefully highlights a social, directional, 'skilful coping' with a world which is understood and worked out in joint action and dialogue with others (Simonson, 2007: 170; Dreher, 2009). The extent to which social contexts engender 'skilful' encounter, embracing conflict as well as cooperation, depends upon the quality of togetherness (Dominelli, 1995). Current debates on the sharing economy rarely consider these micro-social qualities of interaction and togetherness. While it might appear selfevident to state that people have to work hard at working together, this serves to illustrate skills and processes of being, doing and striving that are absent from talk of sharing as an exchange, rather than a social phenomenon.

\section{1 'We' intentions and resolve}

To make connections between individual agency and collectively negotiated, intentional action, it is constructive to reflect on the Hindu concept of Sankalpa; this is defined as a solemn vow or resolve to perform and achieve a goal; not instrumentally, rather, as a union of heart and mind (Zammat, 2017: 192). This is like the way that Giddens (1991: 50) understands motivational drive as 'resolve' to 'commit a life-defining project that matters'. This 'resolve' is future oriented (considering the finitude of human existence) (Fisher, 2010: 242) and it is oriented to others- in the sense that, through participation, self-awareness shifts from 'who I am' to 'what I do' (Zammat, 2017: 192).

Further, to better understand the basis of socially oriented resolve, it is useful to examine the roots of 'we' thinking (Davis, 2002). Mariam Thalos (2008) distinguishes between two expressions of collectivity. The first one defines explicit negotiations amongst members of a group who are known to each other, such as a household (or tribe or intentional community). The second is a shared conception of 'we' that may arise in the absence of prior acquaintance or personal interaction. For example, it is widely recognised that people often think in 'we' terms around relatively intangible assets (non-rivalrous goods in the mosaic above), such as a sense of place, a scenic view, clean air, local heritage and the like. Yet, in the absence of personal interactions leading to explicit negotiations, this 'we' remains implied and 'unresolved'. This collectivity is unlikely to result in joint action (such as 
to preserve a cherished place under threat). Brewer (2003) defines the first collective form as one of association and the second as one of aggregation. These terms capture distinctions inobligations and capacity for cooperation (Thalos, 2008: 92). Growing interest in the origins and development of groups and associations include ways in which they can negotiate norms and obligations- similar to a household or tribe. This is evident in an emerging literature on intentional communities (such as cohousing, ecovillages) and do-ittogether community development.

Social phenomenology highlights the embeddedness and entanglement of individual agency and the 'we-intentions' that shape mutual belief, group phenomena, group goals and joint action (Tuomela, 2005). These structures of 'we' feeling may coincide with those of others who share similar values but they may also evolve dialogically, bound up with persuasion and ethical discernment (Miller, 2004; Strauss, 2008). Cooperation does not function through complete agreement. In cohousing, for instance, the process of reaching consensus on a pet policy, or tending a community garden, can be fraught with conflict, even when this is conducted respectfully through methods of non-violent communication. A joint plan of action calls for highly reflexive deliberation. This entails a manner of conversing that not only empowers the individual, who might otherwise feel excluded, but also entails a playful, creative, learning process (Buur and Larsen, 2010). For instance, Sennett (2012) distinguishes between dialectic and dialogic conversations (see also Carbaugh, 1993). He explains that, while dialectic conversations exchange oppositional views, associated with hierarchical social relations; dialogic conversations allow 'misunderstandings and crosspurposes' to unfold. When doubts are put on the table, people 'must listen harder to one another' (Sennett, 2012: 19).

\section{Degrowth theory and practice}

Degrowth ideas are not new, but in the last ten years they have attracted growing public and academic interest (D'Alisa et al., 2015). In a seminal review of the emerging degrowth literature, Schneider et al., (2010: 511) define this as 'an equitable downscaling of production and consumption that increases human well-being and enhances ecological conditions at the local and global level, in the short and long term'. Degrowth (décroissance in French) has attracted confusion, misunderstanding, scepticism and vigorous critique 
(Fournier, 2008). A special issue of the journal Cleaner Energy in 2010 introduced a new English-speaking audience to the radical holistic contribution that degrowth could offer to the climate change debate (Schneider et al., 2010). The edited book that followed, with essay contributions from 53 scholars from 12 countries, provides a complete overview of current theory and it includes case studies from several intentional communities (D'Alisa et al., 2015). A key distinction is made between unplanned recession, imposed by economic crisis within a growth regime, and a voluntary, smooth and equitable transition to relocalised and low-carbon livelihoods. As Kallis $(2011,875)$ observes, negative GDP growth is not the objective. This has its own name: recession, or if prolonged, depression. By contrast, degrowth pursues alternatives to capitalism that cultivate human flourishing (Krueger et al., 2017: 3).

A degrowth perspective can be identified in the literature with respect to four transformations: extending human relations instead of market relations; deepening democracy; defending ecosystems; and realising a more equal global distribution of wealth. While these ambitions are interrelated, they also reflect colliding and diverse origins and research from a range of physical and social science disciplines. This holistic scope is part of the attraction. As Escobar (2015: 31) observes, we must 'resist falling into the trap of thinking that while the North needs to degrow, the South needs "development". There is an important synergy to be gained from discussing degrowth and alternatives to development in tandem, while respecting their geopolitical and epistemic specificities'. A similar argument is employed here to the co-constitution of sharing practices and lived expressions of togetherness. This is conveyed in the way that social, cultural and voluntary action align with values of 'sharing, solidarity, equality and conviviality' in each of the four degrowth ambitions below (Latouche, 2009: 94, see Sekulova et al., 2013 for a useful review).

\section{Extending human relations instead of market relations}

Degrowth is usefully mobilised as a symbolic weapon or 'missile concept' to 'escape' the 'economic tyranny of neoliberalism and the growth machine logic' and to provoke debate about alternatives (Parker et al., 2007; Kallis, 2011). Escaping the growth paradigm entails an extension of the values and attributes that count toward a 'good life'. In human geography debates, this extension is well established by Kathy Gibson and Julie Graham in 
seminal efforts to articulate diverse marketplaces, as an antidote to capitalist globalization and 'capital-centric' thinking (Gibson-Graham, 2006). Fournier (2008) observes that while the degrowth movement 'shares much of Gibson-Graham's critical intent' it seeks to reembed the constructed nature of economic activities within social and political terms of well-being and citizenship. Accordingly, to 'escape' the economy 'is at least as much a question of decolonizing the imagination as one of enacting new practices, it calls for......rethinking ourselves outside economic relations, for example, by fighting against the reduction of human beings to their economic function, as producers and consumers' (Ariès, 2005; in Fournier, 2008: 534).

Extending human relations resonates with alternative methods of accounting for and 'measuring' diverse local assets, including those of 'Gross National Happiness' (Nørgård, 2013) and intangible heritage (natural and cultural ecologies that we risk losing forever). Intangible qualities of inspiration, learning and wonder- largely rooted in social relationships- tend to be overlooked and discounted by economic discourse and analysis. For example, social attributes of sharing such as combating loneliness can be the least tangible and therefore most overlooked in surveys which target economic value. These less tangible social phenomena of sharing and shared lived experience are retrieved by extending the lens of analysis from person-centred consumer 'choice' to collective action and shared intentions (Belk, 2010; Etzioni, 1998). A social phenomenology of sharing would shift from the question whether to buy Fair Trade bananas, for example, to the socially constructed 'resolve' of 'being' ethical as a life-long project (Marchese et al., 2002; Cloke, 2002). Social movements such as slow food, for example, stress the need to resist 'cultural imperialism' by respecting 'critically endangered' indigenous knowledge and the rhythms of nature (Stefano et al., 2014). It is not that consumption practices are no longer relevant. Rather:

to challenge the 'tyranny of growth', it is not sufficient to call for lesser, slower or greener growth for this would leave us trapped within the same economic logic; rather we need to escape from the economy as a system of representation. This means re-imagining economic relations, identities, activities in different terms; and it is to this end that the degrowth movement puts forward the notions of democracy and citizenship (Fournier, 2008: 529). 
Degrowth highlights social and cultural ecologies and 'we' associations that flourish outside chains of consumption and production (Fournier, 2008: 534).

\section{Deepening democracy}

Equally vital to the extension of human relations is a deepening of democracy. This again resonates with theories of 'solidarity economies' (Reintjas, 2003), but with renewed emphasis on releasing people from 'disabling market intensity' (Illich, 1978) by reducing wage-work and freeing up time for family, culture and community (Hayden, 1999). Nørgård, (2013: 62) argues that whereas the growth paradigm is based on consumer debt, conspicuous consumption, waste and the rapid obsolescence of everyday gadgets and appliances, degrowth links up with sharing-basedsocial movements that seek to reduce paid work time and consumption. Rather than a 'circular economy', this 'virtuous' downshifting serves to mitigate environmental degradation while at the same time improving people's general well-being. This is not about increasing leisure time, which in western societies is to a large extent bound up with creating more work through ever-increasing consumption (Nørgård, 2013: 64; Mansvelt, 2008). Rather, the expectation is to return some forms of production to non-monetary volunteer activity. This resonates with the 'craft skills' of collaboration that are observed to provide a source of satisfaction, whether to produce an output (in a system largely controlled by others), or as an activity that is intrinsically satisfying in itself (Sennett, 2008).

Extending human relations coincides with an extended range of regional democratic practices that highlight contested and differentiated knowledge of what collaboration and sharing entails and how to catalyse it (Clark and Teachout, 2012). For example, David Orr (1997) connects 'slow' knowledge (indigenous cultural ecologies) with the voluntary collective learning required in cooperative association. Both are evident in degrowth policy. Examples include a 21-hour working week, basic income for all, campaigns to leave oil in the ground, to cap CO2 and to cap salaries (see www.degrowth.eu and http://www.neweconomics.org/). The idea is that demands such as these serve to 'create broader social coalitions, including not only environmentally concerned groups, but also trade unions, precarious workers and the unemployed or environmental justice movements in the Global South' (Kallis, 2011: 878). 


\section{Defending ecosystems}

Publication of the original Limits to Growth in 1972 launched the first incarnation of a broad anti-growth movement that drew attention to the intimate relationship between human activity and environmental loss. This was influential because it was controversial: the authors were lambasted for putting 'nature before society' (Meadows et al., 1972). By the time the first Earth Summit convened in Rio in 1992 a more moderate form of 'technocentric' environmental movement prevailed, as expressed in the dominant ideology of 'sustainable economic development'. Environmentalists have since continued to point out that this oxymoron serves to 'sustain the unsustainable' (Fournier, 2008). Accordingly, a holistic approach to resource depletion and waste disposal is key to defending the rights and intrinsic values of the ecosystem, challenging the ways that neoliberalism discounts the degradation or transformation of carbon energy, even as it is claimed through the sharing economy to be recycled or reused in a different entity (Georgescu-Roegen, 1971). Sustainable degrowth thus defends the rights and intrinsic value of an integrated ecosystem (Bonaiuti, 2012). The absurdity of an economic system based on 'growth' when what is meant to 'grow' remains arbitrary resonates with green politics and the transitions movement (Scott-Cato, 2006). Thus, by conventional economic accounting, increasing cancers, road accidents, obesity, ecological disasters, and wars- all contribute to economic growth through the consumption of insurance, medical products and services, cleaning industry, weapons and so on (Fournier, 2008: 531).

\section{Realising a more equal distribution of wealth}

Efforts to realise a more equal distribution of wealth correspond with two interrelated socio-spatial spheres. On the one hand, degrowth theory seeks to challenge and transform the assumptions of hegemonic modernity, whereby all development is defined in terms of economic development, imposing western industrial models of capital, science and technology as the solution to the 'problem' of under-developed areas (Escobar, 2015: 29). Sustained criticism of hegemonic development ideology coincides with grassroots initiatives of indigenous social philosophies seeking to 'break away from the cultural and ideological bases of development, bringing forth other imaginaries, goals and practices' (Gudynas, 2015: 202). Current examples include Buen Vivir (collective well-being) in Ecuador, the 
Gandhian Economy of Permanence in India, and grassroots groups committed to a postextraction transition to the Rights of Nature (Escobar, 2015; Giovannini, 2014).

On the other hand, degrowth theory also emphasises the post-material well-being goal of sufficiency, rather than unlimited growth (Princen, 2005). Efforts to deepen democracy also function through a broad base of relationships reaching across civil society, forging common ground in alliance, as illustrated in the case of London Citizens and the living wage campaign (Wills, 2012). The argument is that living standards and fairness can be improved and maintained by properly valuing intangible non-economic attributes of well-being, including 'we' intentions and resolve to realise a more equal distribution of wealth (Princen, 2005). The social justice arguments of sufficiency are illustrated in the example of basic income policies and work-time reduction alongside localized food production and shared alternatives to private property (Hayden, 1999: 3; Bregman, 2017: 149).

While a growing number of different groups and movements demonstrate and publicise that they are putting degrowth ideas into practice, critics point to the lack of focus and coherence represented by this 'fuzzy' term (see for instance Trapeze Collective, 2008). Stephen Quilley (2013: 265) argues that degrowth (and peak oil transition) movements are utopian because they de-emphasise the role of social conflict. Countering the traditional 'small is beautiful' image of harmonious self-regulation, Quilley (2013: 280) claims that the smaller and more local the scale of living, 'the more likely its political and social structure will be illiberal and marked by higher levels of interpersonal violence'. In response, Bonaiuti (2012) insists that the degrowth vision is not a quest for utopia. As with utopian studies, degrowth scholarship is hindered, for some critics, by the absence of living expressions (Schehr, 1997). Yet, as Kallis and March (2014: 361) observe, 'there is theory and there are small experiments broadly inspired by degrowth, but there is not a spatialized 'degrowth world in its full plenitude'. Nevertheless, this open and experimental agenda offers many strengths over a 'fixed blue-print' view of the future. Much in the same way that Ruth Levitas (2007) advances a utopian method of thinking, as a process of criticism and creativity, the degrowth movement in its multiple schools offers a subversive 'space to think and imagine with'. It subverts the hopeless dictum that 'there is no alternative' with 'conditions of possibility' (Gibson-Graham, 2006), replacing this with an improvised, 
collaborative process of learning through experimentation. Arguably, denying the imperative of growth is not synonymous with turning back the clock to a pre-industrial, selfsufficient past but, rather,constructing an alternative future (Schneider et al., 2010).

\section{On the social phenomenology of togetherness}

Current debates on the sharing economy typically assume that all transactions are 'intentional' in that they are voluntary and free of coercion. Yet, as argued above, there is more to intentionality than agency. Distinctions can be made between purposeful (politically progressive) sharing and 'instrumental' or 'serendipitous' transactions. While it is constructive to elaborate the multiple and complex aspects of sharing, as in the 'mosaic' above, there has arguably been a tendency to over-emphasise new opportunities for consumption, focusing on individual 'choice,' rather than what prevents people from consciously organising against consumption from a degrowth perspective (Goss, 2004; Popke, 2006). As Anders Hayden (1999: 180) observes, capital systems are devised to meet basic needs (such as housing, transportation, food, healthcare, clothing, education and economic security) individually, in ways that actively encourage over-consumption (trading up to a bigger home, a second car to coordinate multi-wage earning households and nonlocal education, more pre-packaged food to enable a faster pace of life) and they obstruct the kind of collective engagement required of a truly 'alternative' ethos (Segal, 1999: 8). Closer scrutiny of the micro-sociology of 'shared intentionality', including the capacity to engage in more communal living arrangements, has so far received less attention in debates on sharing (Tomasello and Moll, 2010: 331).

Renewed interest in communal 'togetherness' is highlighted in two popular ethnographies that explore small self-organising groups, including voluntary associations, church groups, clubs and civic societies (Sennett, 2012; Hemmings, 2011). Both offer a timely counter-point to hackneyed concern for the decline in social trust and associational life over the past half century. Robert Putnam's (2000) thesis Bowling Alone epitomises this. Rather than directly challenge accounts of increasing individualism and diminishing connections between people and the places in which they live and work, Richard Sennett (2012) highlights the rich but fragile nature of these poorly understood associational relations. To develop this argument, three discrete types of 'togetherness' are identified below from the social phenomenon 
involved, notably opportunities, and resolve, to understand and respond to one another in order to act together: living togetherness; thrown togetherness; and intentional togetherness. Within this framework, closer scrutiny of forming cohousing groups reveals a process of working together jointly that is as significant as the goal or outcome of sharing domestic space: collaboration provides a catalyst for deeper levels of trust and cooperation.

\section{Living togetherness}

Traditional inner city neighbourhoods superficially present everyday opportunities for interactions between neighbours living together in 'close-knit' arrangements of housing, shops, schools, cafes and pocket parks. While Philip Abrams associates the neighbour with social contact defined by shared location and a material living-togetherness, Joe Painter (2012) advances a more nuanced account of an ambivalent figure. Accordingly:

proximity matters, not because it forces the neighbours to interact, but because it gives them the opportunity to do so. Their relationship is so fragile and episodic that it is hard to imagine it developing at all without the accident of propinquity. Under these conditions of possibility, successive encounter-can generate mutual regard and understanding- whereby attachment builds slowly (Painter, 2012:527).

This is the ideal form of 'neighbourliness' that hyper-local P2P promulgate.

In modern neighbourhoods the 'natural' desire for neighbours to enjoy the physical company of others living nearby is apparently not only fragile and selective but susceptible to counterfeit. John Frei (1998: 177) claims that the enduring myth of the 'ideal community' is exploited in marketing strategies such as housing developments designed to evoke the look and feel of an 'urban village'. Feelings of connectedness that characterize genuine community require the skills and experience of building bonds of association through 'honest recognition of disagreements', the resolution of those disagreements, the forging of agreements to work together, and the building of consensus about basic values and beliefs that unite people (Christensen and Levin, 2003: 347). By contrast, counterfeit community only requires that people desire the impression of togetherness (Frei, 1998: 177).

\section{Thrown togetherness}


According to Heidegger (1962), we are 'thrown' at birth into one place in the world and 'brought up in ways that not only contingently prefigure our ideas and beliefs but, in so doing, cut all of us off from any direct knowledge or easy road to enlightenment' (Zeng, 2014: 138). Doreen Massey advanced this idea in relation to individual 'resolve', introduced above, in her writing on the movement of people within and between regions around the world. She recognised that how we come to live with each other in a particular place is dynamic. Moreover, this 'ever-shifting constellation of trajectories' (Massey, 2005: 151) suggests not only a 'thrown' togetherness of previously settled residents, rubbing up against newcomers, but also the impulse to construct a meaningful life and to 'belong'. This is illustrated by considering that 'being in the world' is contingent upon lives folded in upon and unfolding with others.

Questions of connection and solidarity in different cultural groups interacting in the public space of the modern city lie at the heart of the politics of place. Ash Amin (2004, 2012) elaborates on what he observes to be a politics of propinquity in cities and public spaces (including the internet) by which sharing practices are revealed in an ethic of care for the stranger (Amin, 2012). Doreen Massey (2005) similarly articulates this intermingling as a 'thrown togetherness' of disenfranchised people congregating in marginal spaces. This approach considers the political and cultural force of conviviality in togetherness as a measure and means of generating civic solidarity beyond the nation-state (Stevenson, 2006: 487). It seeks to make the connection between two territorial scales; public space as a site of fleeting encounters; and values and identities forged in civil society though the politics of national and regional citizenship. Further ambiguity is evident when formal public spaces are transformed by temporary occupation. As Vasudeven (2014) observes, with respect to squatting, precarious existence tends to demand a form of 'extracted sociality' and 'complex forms of deliberation' that can bring about new expressions of mutuality and sharing (Vasudevan, 2014: 353). Again, it is critical to look beyond 'togetherness in propinquity' to the quality of collaboration entailed, as with a mutually recognised commitment to joint action and the intention of each to coordinate his or her actions with each other's (Pavitt and Hopkins, 2004; Tuomela, 2005). 
Missing from this politics of fleeting encounter, whether virtually mediated or physically enacted, is further consideration of the challenges of people 'rubbing along' with strangers, whether as internet users or co-existing in public space when rights to privacy and property are enacted through a fragile choreography of legal and normative codes of behaviour. Doing so suggests a counter-point to the implied positive and often romantic or parochial connotations of 'place' and 'community' (Pavitt and Hopkins, 2004: 105).

\section{Intentional togetherness}

Shared and social time, whether on the scale of one shared house or multiple connected or clustered homes, is about providing a more integrated social and economic space (Jarvis, $2011,2013)$, to reduce costs of living and waste and attend to questions of justice and redistribution between inhabitants and neighbouring places with different economic and ecological endowments (McLaren and Agyeman, 2015; North, 2010; Illich, 1973). While intuitively, sharing intentional togetherness conjures images of parochial interaction, any well-rehearsed, repeated group solidarity can function through digitally mediated social proximity, as with the virtual village, or as a hybrid of real and virtual interactions (Wellman, 1999). Similarly, many features of progressive urban politics align with localisation. Yet, the emerging literature on intentional communities (such as cohousing and the ecovillage), and do-it-together local social enterprise, illuminates opportunities for meaningful interaction, mutuality and sharing that do not exist in stretched out or virtual networks of sociality (Tuomela, 2007, Melucci, 1989).

The Intentional Community is characterised by a group of member-residents living together (under one roof or many). Degrees of sharing vary from the very highest level of income sharing (what is often labelled a commune or kibbutz) (Manzella, 2010), to looser arrangements combining private and shared resources (such as with cooperatives, ecovillages and cohousing) (Jarvis, 2011; 2015). Motivations for people to choose to live communally or collectively are diverse. The positive connotations of collaboration and purpose, including questions as to whether this shared arrangement allows all residents (or a select few) to shape and influence domestic arrangements in socially progressive ways remain a moot point (see for instance Shroeder, 2007). Indeed, a continuum of intentionality suggests 'selective solidarity' whereby, in contemporary cohousing, for 
instance, mechanisms for greater sharing coincide with considerable protection of privacy. Neither should it be concluded from this emphasis on intentionality that 'thrown' states of living together are inevitably hostile or exclusive.

While it is not possible in this article to elaborate on multiple intersecting expressions of communality, it is important to stress that it is the social architecture (of learning, being and doing as a group), rather than the material setting, that aligns cohousing with a degrowth paradigm (Jarvis, 2015). As Mattheiu Lietaert (2010) argues, cohousing establishes a joinedup, holistic system for learning about, and enacting, the behaviour changes necessary to reduce consumption and the 'earn to spend' treadmill of debt-and-wage-based livelihood.

\section{Purpose, proximity and pragmatism}

Cohousing differs from 'accidental' or 'master-planned' neighbourhood clusters because it represents an intentional community; a 'group of people who have chosen to live (and sometimes work) together for some common purpose beyond that of tradition, personal relationship or family ties' (Sargisson, 2000: 1). The understanding is that neighbour relations are more meaningful and mutually supportive when homes and communities are co-produced - 'self-made' rather than 'ready-made'. Jennifer Wolch (2007) traces the growth of new social movements which seek to resist and ameliorate the waste of overconsumption. She is among the first wave of human geographers to deploy a degrowth argument, even without using this term. This encourages Kallis and March (2015) to urge human geographers to pay more attention to degrowth theory and practice when debating the structural and behavioural changes needed to address climate change. Connections are thus made between social movements of voluntary simplicity and alternative lifestyle communities such as cohousing and eco-village initiatives. In cohousing, co-presence and affiliation actively facilitate instrumental sharing to reduce waste (Ahrentzen, 1996: 50).

Elsewhere it is observed that intentional and collaborative neighbourhood arrangements thrive on multiple co-constitutive proximities; social proximity (affiliation and shared endeavour), combined with spatial proximity (co-presence) (Jarvis, 2015: 98). While proximity is necessary for residents to practice sharing (by regularly meeting and interacting to agree common values), neighbourliness is not sufficient as a means for mutual support to 
flourish. For example, enduring affiliations and skilful cooperation, typically shaped by individuals who are known to be effective facilitators, evolve from the repeated rituals and work of preparing and taking meals together (Ludwig, 2017: 34). Shared work that reconnects individuals to each other and a collective sense of stewardship is identified as among the most crucial, least well theorized expression of sharing in practice (Meltzer, 2005).

\section{Conclusion}

The discussion above critically reflects on discrete concepts of 'sharing', 'togetherness' and 'intentionality'. Each is individually ambiguous and widely associated with multiple, fluid and contested meanings. While each individually warrants further interpretation, as with new literature on the process of 'meaning making' in diverse economies, including product sharing and leasing schemes (Krueger et al., 2017, 13; John, 2017), these social phenomena are more accurately understood as co-constitutive. Thus, a social phenomenology is proposed here that captures intersecting socio-spatial and ethical qualities to the ways that people engage with, and collectively negotiate access to, assets, resources, time and skills. This argument should not be confused with a simplistic binary distinction between virtual and material sharing practices (Richardson, 2015). Instead, by scrutinising contextual qualities of togetherness (the constrained neighbourliness of conventional homes and communities; the proximity of relative strangers 'thrown together' in public space; and the purposeful cohabitation of intentional neighbourhoods of cohousing), this article draws attention to capabilities and processes of meaningful social interaction that can resist rather than reinforce neoliberal growth.

The degrowth perspective that threads through this article draws on recently translated French 'socio-cultural' and German 'post-material' literature and debate (D'Alisa et al., 2015). Muraca and Schmelzer (2017) identify three discrete 'language regional' bodies of degrowth; the 'décroissance socio-cultural critique of Western development in France and Southern European countries (Gorz, 1999; Muraca, 2013); the 'arrested development' of degrowth in the English-language literature (Jackson, 2009; Daly, 1980); and the Germanlanguage 'post-growth' debate, best known for addressing roles of work and employment

(including basic income ideas) and non-capitalist forms of domestic provisioning (Hayden, 
1999; Bregman, 2017; see also Illich, 1978). Within this typology, the English-language growth critique is originally distinguished by narrow roots in heterodox ecological economics, followed by sophisticated advancements in diverse alternative economic spaces (Muraca and Schmelzer, 2017: 180). While this article favours the interdisciplinary breadth and socio-spatial integration of the French and German schools, by reviewing a wide range of conceptual literature, as here, it is possible to advance a social phenomenology that supplements, without supplanting, existing seminal contributions to human geography, notably those challenging the assumptions of hegemonic modernity and those giving rise to differentiated indigenous social philosophies and knowledges (Gibson-Graham, 2008; Miller, 2004; Reintjas, 2003).

Navigating evident splits and disagreements in degrowth thinking is not without hazard. Moreover, while cohousing is identified here as a practical solution of integrated transformation (seeking not only to reduce consumption and waste but also to reduce paid work time and return forms of production to non-monetary social reproduction activity), this is at best a partial, pragmatic interpretation of a more radical growth critique. In its defence, it is because the 'look and feel' of cohousing is relatively mainstream that it demonstrates a viable alternative to capitalism in a housing context (Williams, 2008; Jarvis, 2015).

A key contribution that this article offers, distinct from growth critiques that have gone before, is to shine a light on the micro-social processes at work at the intersections of sharing, togetherness and intentionality. This responds to Richard Belk's (2014) call for conceptual analysis that explicitly considers how sharing and togetherness can be harnessed progressively to disrupt the socially divisive impact of neoliberal growth. The conceptual discussion above illustrates how groups and associations cultivate social processes of experimentation that find limited scope in macro-economic research, governance and policy. As Lietaert (2010: 580) observes, there is 'no evidence that long-term public policies are being implemented to reduce the existing high level of stress, competition and housing prices, or to favour a better quality of interpersonal relations. To the contrary, hyperindividualism keeps growing'. From this perspective, social phenomenology reveals how people collaborate with others, finding common ground in collectively negotiated 
subjectivities. It signals that social norms of 'growthmania' are more effectively challenged by coordinated and convivial action. A good example is to contrast the reduced consumption that can be achieved cooperatively in cohousing, with individual practices of voluntary simplicity (Etzioni, 1998; Hayden, 1999). The latter remains constrained by capital systems, such as conventional single-family dwelling (Jarvis, 2013).

Recognising the intangible qualities of interpersonal relations of affiliation, this article retrieves a fundamentally social, anthropological appreciation of social organising against expectations of growth. It emphasises not only the possibilities of meaningful social connection and interaction but, more significantly, the empowerment catalysts these relationships endow- the social phenomenon of being and doing 'we' not 'I'. This acknowledges recet advancements in human geography debates that recognise civic, nonconsumer, ethical registers, such as community sharing (Clarke et al., 2007: 231; Mansvelt, 2008), and the lessons to be learned from taken for granted care-giving relationships for a more moral geographical thought and practice (Tronto, 2009; Lawson, 2007). At this same time, it highlights the need for further theoretical and empirical work to address the paradoxical contribution of sharing economies to the growth paradigm (Huneke, 2005; Jarvis, 2010).

These contradictions are well-known and widely reported in the literature and debate on diverse and alternative economies. As Krueger et al., (2017: 16) observe:

in shaping new, largely unregulated markets, internet-based peer-to-peer activities have attracted investors following more traditional ideas of profit maximisation and surplus allocation. Many of the big players in this so-called platform economy (e.g. Airbnb, Uber) thus tend to create what Martin (2016: 149) has called 'a nightmarish form of neoliberalism' rather than a potential pathway to sustainability.

Due to the persistent focus on individualised consumption, most efforts to promote sustainability through ethical, responsible and 'green' consumption fail to address the imperative to consume considerably less and to do so collectively, rather than individually. Emphasising ways of reducing, reusing and recycling goods through efficient internet user interactivity miss the point. By contrast, intentional sharing and togetherness call for a higher level of understanding and consciousness about what we're doing here and why. As 
a call for further research, this suggests greater need for deeper understanding of the social, collective and political entanglements of the sharing paradigm, including micro-social engagement in more collaborative and communal ways of living sustainably.

\section{$\underline{\text { References }}$}

Agyeman J, McLaren D and Schaefer-Borrego A (2013) Sharing Cities: A 'Big Ideas' Project for Friends of the Earth. London:

http://www.foe.co.uk/sites/default/files/downloads/agyeman sharing cities.pdf

Ahrentzen S (1996) Housing alternatives for new forms of households. In Hemmens GC, Hoch CJ and Carp J (eds) Under one roof: Issues and innovations in shared housing. New York: State University Press. 49-63.

Amin A (2004) Regions unbound: towards a new politics of place. Geografiska Annaler, Series B, Human Geography 86(1): 33-44.

Amin A (2012) Land of Strangers. Oxford: Polity

Ariès P (2005) Décroissance ou Barbarie. Lyon: Golias.

Ash J and Simpson P (2016) Geography and post-phenomenology. Progress in Human Geography 40(1): 48-66.

Bakhtin M (1986) Speech Genres and Other Late Essays, translated by V.W. McGee. Austin, TX: University of Texas Press.

Belk R (2010) Sharing. Journal of Consumer Research 36(5): 715-734.

Belk R (2014) Sharing versus pseudo-sharing in Web 2.0, Anthropologist 18(1): 7-23.

Belk R (2014a) You are what you can access: Sharing and collaborative consumption online. Journal of Business Research, 67(8): 1595-1600.

Bonaiuti M (2012) Growth and democracy: trade-offs and paradoxes. Futures 44(6): 524-534.

Botsman R (2010) What's Mine is Yours: The Rise of Collaborative Consumption. New York: Harper Business.

Bregman, R. (2017) Utopia for Realists and How We Can Get There. London: Bloomsbury.

Brewer T (2003) Two kinds of commitment (and two kinds of social groups). Philosophy and Phenomenology Review 66: 554-53. 
Brown J and Morgan J (2006) Reputation in online auctions: The market for trust. California Management Review 49(1): 61-81.

Buur J and Larsen H (2010) The quality of conversation in participatory innovation. CoDesign 6(3): 121-138.

Carbaugh D (1993) Communal voices: an ethnographic view of social interaction and conversation. Quarterly Journal of Speech 79(1): 99-113.

Christensen and Levinson (eds) (2003) Encyclopedia of Community: From the Village to the Virtual World (Vol.1). New York: Sage, 347.

Clark S and Teachout W (2012) Slow Democracy: Rediscovering Community, Bringing Decision Making Back Home. New York: Chelsea Green Publishing.

Clarke N, Barnett C, Cloke P and Malpass A (2007) Globalising the consumer: doing politics in an ethical register, Political Geography 26: 231-249.

Cloke P (2002) Deliver us from evil? Prospects for living ethically and acting politically in human geography. Progress in Human Geography 26(5): 587-604.

Crang M, Hughes A, Gregson N, Norris L, and Ahamed F (2013) Rethinking governance and value in commodity chains through global recycling networks. Transactions of the Institute of British Geographers 38(1): 12-24.

D’Alisa G Demaria F and Kallis G (Eds) (2015) Degrowth: A Vocabulary for a New Era. London/ New York: Routledge.

Daly H E (1980) Economies, Ecology, Ethics. Essays Toward a Steady-State Economy. San Francisco: W.H. Freeman \& Co.

Davis J B (2002) Collective intentionality and individual behaviour. In Fullbrook E (ed). Intersubjectivity in Economics: Agents and Structures. New York: Routledge, 11-27.

Degrowth (2016) http://www.degrowth.org/ (accessed 21 ${ }^{\text {st }}$ August 2016)

Doherty D and A Etzioni (2003) Voluntary simplicity: Responding to consumer culture. Oxford: Rowman and Littlefield.

Dominelli $L$ (1995) Women in the community: feminist principles and organising in community work. Community Development Journal 30: 133-143.

Dreher J (2009) Phenomenology of friendship: construction and constitution of an existential social relationship. Human Studies 32: 401-417.

Entrikin J N and Tepple J H (2006) Humanism and democratic place-making. In S. Aitken and G. Valentine (eds) Approaches to Human Geography. Thousand Oaks, CA.: Sage, 30-41. 
Escobar A (2015) Critiques of development. In D'Alisa G, Demaria F and Kallis G (eds) Degrowth: A Vocabulary for a New Era. London/ New York: Routledge, 29-32.

Etzioni A (1998) Voluntary simplicity: characterization, select psychological implications, and societal consequences. Journal of Economic Psychology 19: 619-643.

Fisher T (2010) Heidegger and the narrativity debate. Continental Philosophy Review 43(2): 241-265.

Fournier V (2008) Escaping from the economy: the politics of degrowth, International Journal of Sociology and Social Policy 28.11/12: 528-545.

Freie J F (1998) Counterfeit community: The exploitation of our longings for connectedness. New York: Rowman \& Littlefield.

Gabriel R (2013) Why I buy: Self, Taste, and Consumer Society in America. Chicago: University of Chicago Press.

Georgescu-Roegen N (1971) The Entropy Law and the Economic Process. Cambridge: Harvard University Press.

Gibson-Graham J K (2003) Enabling ethical economies: cooperativism and class. Critical Sociology 29(2): 123-161.

Gibson-Graham J K (2006) A Postcapitalist Politics. Minneapolis, MN: University of Minnesota press.

Gibson-Graham J K (2008) Diverse economies: performative practices for 'other worlds' Progress in Human Geography 32(5): 613-632

Giddens A (1991) Modernity and self-identity: Self and society in the late modern age. Stanford: Stanford University Press.

Giovannini M (2014) Indigenous community enterprises in Chiapas: a vehicle for buen vivir? Community Development Journal 50(10: 71-81.

Gorz A (1999) Reclaiming Work: Beyond the Wage-Based Society. Cambridge: Polity Press.

Goss J (2004) Geography of consumption I. Progress in Human Geography 28(3): 369-380.

Gudynas E (2015) Buen Vivir. In D'Alisa G, Demaria F and Kallis G (eds) Degrowth: A Vocabulary for a New Era. London/ New York: Routledge: 201-205.

Hayden A (1999) Sharing the Work, Sparing the Planet: Work, Time, Consumption and Ecology. London and New York: Zed Books. 
Kenyon, E., \& Heath, S. (2001) Choosing this life: narratives of choice amongst house sharers. Housing Studies 16(5), 619-635.

Heidegger M (1962) Being and Time. Oxford: Blackwell.

Hemmings H (2011) Together: How Small Groups Achieve Big Things. London: John Murray

Hobson K (2016) Closing the loop or squaring the circle? Locating generative spaces for the circular economy. Progress in Human Geography 40(1): 88-104.

Huneke M E (2005) The face of the un-consumer. An empirical examination of the practice of voluntary simplicity in the United States. Psychology \& Marketing 22 (7): 527-50.

Illich I (1973) Tools for Conviviality. London: Marion Boyars (2009 reprint)

Illich I (1978) The Right to Useful Unemployment and its Professional Enemies. London: Marion Boyars (2009 reprint).

Jackson P (1981) Phenomenology and social geography. Area 13: 299-305

Jackson T (2009) Prosperity Without Growth: Economics for a Finite Planet. London: Earthscan.

Jarvis $\mathrm{H}$ and Bonnett $\mathrm{A}$ (2012) Progressive nostalgia in novel living arrangements: a counterpoint to neo-traditional new urbanism? Urban Studies 50(11): 2349-2370.

Jarvis $H$ (2010) On not keeping up with the Joneses: is it 'alternative' not to shop? In: Fuller D, Jonas AEG and Lee R (eds) Interrogating Alterity: Alternative Economic and Political Spaces. Farnham: Ashgate, 131-145.

Jarvis H (2011) Saving space, sharing time: integrated infrastructures of daily life in cohousing. Environment and Planning A 43(3): 509-762.

Jarvis H (2013) Against the 'tyranny' of single-family dwelling: insights from Christiania at 40. Gender, Place \& Culture 20(8): 939-959.

Jarvis $H$ (2015) Towards a deeper understanding of the social architecture of cohousing: evidence from the UK, USA and Australia. Journal of Urban Research and Practice 8(1): 93105.

John N A (2017) The Age of Sharing. Oxford: Polity.

Kallis G (2011) In defense of degrowth. Ecological Economics 70: 873-880.

Kallis G and March H (2015) Imaginaries of hope: the utopianism of degrowth. Annals of the Association of American Geographers 105(2): 360-368. 
Kanter R M (1976) Roots Versus Restlessness: Cooperative Households, the City, and Recurrent Issues in American Family Life. The Massachusetts Review 17(2): 331-53.

Krueger R, Schutz C and Gibbs D (2017) Institutionalizing alternative economic space? An interpretivist perspective on diverse economies. Progress in Human Geography 1-21. DOI:10.117703093257694530

Latouche S (2009) Farewell to Growth. Cambridge: Polity Press.

Lawson V (2007) Geographies of care and responsibility. Annals of the Association of American Geographers 97(1): 1-11.

Levitas R (2007) Looking for the blue: The necessity of utopia. Journal of Political Ideologies 12(3): 289-306.

Lietaert M (2010) Cohousing's relevance to degrowth theories. Journal of Cleaner Production 18: 576- 580.

Ludwig M (2017) Together Resilient: Building Community in the Age of Climate Disruption. Rutledge. MO: Fellowship of Intentional Community.

McLaren D and Agyeman J (2015). Sharing Cities: A Case for Truly Smart and Sustainable Cities. MIT Press.

Maniates M F (2001) Individualization: Plant a tree, buy a bike, save the world? Global environmental politics 1(3): 31-52.

Mansvelt J (2008) Geographies of consumption: citizenship, space and practice. Progress in Human Geography 32(1): 105-117.

Manzella J C (2010) Common Purse, Uncommon Future: the Long, Strange Trip of Communes and Other Intentional Communities. Santa Barbara, Ca.: Praeger.

Marchese M C, Bassham G and Ryan J (2002) Work-family conflict: a virtue ethics analysis. Journal of Business Ethics 40: 145-154.

Martin CJ (2016) The sharing economy: a pathway to sustainability or a nightmarish form of neoliberal capitalism? Ecological Economics 121: 149-159

Massey D (2005) For Space. London: Sage

Meadows D H, Meadows D L, Randers J and Behrens W W (1972) The Limits to Growth: A Report of the Club of Rome's Project on the Predicament of Mankind. London: Earth Island Limited. 
Melucci A (1989) Nomads of the Present: Social Movements and Individual Needs in Contemporary Society. Vintage.

Meltzer G (2005) Sustainable Community: Learning From the Cohousing Model. Victoria, BC: Trafford.

Miller E (2004) Solidarity Economics: strategies for building new economies from the bottom up and the inside out

(http://ussen.electricembers.net/files/SolidarityEconomicsEthanMiller.pdf) Accessed online 15 July 2013

Molotch H (2003) Where stuff comes from: How toasters. Toilets, Cars, Computers, and Many Other Things Come to Be as They Are. New York: Routledge.

Muraca B and Schmelzer M (2017) Historical roots of the search for alternatives to growth in three regions. In Borowy I and Schmelzer M (eds) History of the Future of Economic Growth: Historical Roots of Current Debate in Sustainable Degrowth. New York: Routledge, 174-197.

Muraca B (2013) Decroissance: a project for a radical transformation of society. Environmental Values 22(2) 147-169

Nelson M R, Rademacher M A and Paek H J (2007) Downshifting consumer= upshifting citizen? An examination of a local freecycle community. The Annals of the American Academy of Political and Social Science 611(1): 141-156.

Nørgård J (2013) Happy degrowth through the more amateur economy. Journal of Cleaner Production 38, 61-70.

North P (2010) Unsustainable urbanism? Cities, climate change and resource depletion: a Liverpool case study. Geography Compass 4(9): 1377-1391.

Orr D W (1996) Educating for the environment: higher education's challenge of the next century. The Journal of Environmental Education 27(3): 7-10.

Painter J (2012) The politics of the neighbour. Environment and Planning D 30: 515-533

Parker M, Fournier V and Reedy P (2007) The Dictionary of Alternatives: Utopianism and Organization. London: Zed Books.

Pavitt C and Hopkins J (2004) Cooperative discussion in a group setting. Atlantic Journal of Communication 12(2): 105-119.

Pickles J (1985) Phenomenology, science and geography. Cambridge: Cambridge University Press. 
Popke J (2006) Geography and ethics: everyday mediations through care and consumption. Progress in Human Geography 30(4): 504-512.

Price J (1975) Sharing: the integration of intimate economies. Anthropologica 17(1): 3-27.

Princen T (2005) The Logic of Sufficiency. Cambridge: MIT Press.

Putnam R (2000) Bowling Alone: The Collapse and Revival of American Community. New York: Simon and Schuster.

Quilley S (2013) De-growth is not a liberal agenda: relocalisation and the limits to low energy cosmopolitanism. Environmental Values 22(2): 261-285.

Ray D (2016) The Collective, Old Oak, London: collective nightmare. London: Icon magazine. The https://www.iconeye.com/opinion/comment/item/12482-collective-nightmare

Reintjas C (2003) What is a Solidarity Economy? Life After Capitalism Talks, World Social Forum III, Porto Alegre: Brazil. Available at: http://www.zmag.org/carolase.htm (accessed 14 July 2016).

Richardson L (2015) Performing the sharing economy. Geoforum 67: 121-129.

Rossa J (2015) The sharing economy by any other name. Bloomberg Brief. June $15^{\text {th }} 2015$. https://newsletters.briefs.bloomberg.com/document/4vz1acbgfrxz8uwan9/namingconventions (accessed 18th August 2016).

Sargisson L (2000) Green utopias of self and other. Critical Review of International Social and Political Philosophy 3(2-3): 140-156.

Schehr R C (1997) Dynamic Utopia: Establishing Intentional Communities as a New Social Movement Westport, CT.: Bergin and Garvey.

Schiffere J (2013) Sharing our way to prosperity (Part 1) and Profiting from Sharing (Part 2). RSA Blog Entries. Available at: http://www.rsablogs.org.uk/2013/social-economy/sharingprosperity/ (Access 18 ${ }^{\text {th }}$ August 2016).

Schmidt MFH and Sommerville J A (2011) Fairness Expectations and Altruistic Sharing in 15Month-Old Human Infants. PLoS ONE 6(10): e23223. doi:10.1371/journal.pone.0023223

Schneider F, Kallis G and Martinez-Alier J (2010) Crisis or opportunity? Economic degrowth for social equity and ecological sustainability. Introduction to this special issue. Journal of Cleaner Production 18: 511-518.

Segal JM (1999) Graceful Simplicity: Towards a Philosophy and Politics of Simple Living. New York: Holt. 
Shroeder K (2007) A feminist examination of community kitchens in Peru and Bolivia. Gender, Place and Culture 13 6(1): 663-668.

Schutz A (1970) On Phenomenology and Social Relations Chicago. Chicago: The University of Chicago Press

Scott-Cato M (2006) Market, Schmarket: Building the Post-Capitalist Economy. Cheltenham: New Clarion Press.

Seamon D (2000) A way of seeing people and place: phenomenology in environmentbehaviour relations. In Wapner S, Demick J, Yamamoto T and Minami H (eds) Theoretical Perspectives in Environment-Behaviour Research. New York: Plenum, 157-78.

Seamon D (2006) A geography of lifeworld in retrospect: a response to Shaun Moores Particip@tions 3 1-13. Available at:

http://www.participations.org/volume\%203/issue\%202\%20-\%20special/3_02_seamon.htm) Accessed 12 June 2013.

Sekulova F, Kallis G, Rodríguez-Labajos B and Schneider F (2013) Degrowth: from theory to practice. Journal of Cleaner Production 38: 1-6.

Sennett R (2008) The craftsman. New York: Yale University Press.

Sennett R (2012) Togetherness. London: Allen Lane.

Seyfang G (2010) Community action for sustainable housing: building a low-carbon future. Energy Policy 38: 7624-7633.

Simonson K (2007) Practice, spatiality and embodied emotions: an outline of a geography of practice Human Affairs 17: 168-181.

Stefano M L, Davis P \& Corsane G (eds) (2014) Safeguarding intangible cultural heritage (Vol. 8). Boydell \& Brewer Ltd.

Strauss K (2008) Re-engaging with rationality in economic geography: behavioural approaches and the importance of context in decision-making. Journal of Economic Geography 8: 137-156

Sundararajan A (2016) The Sharing Economy: The End of Empty and the Rise of Crowd-Based Capitalism. Cambridge: MIT Press.

Thalos M (2008) Two conceptions of collectivity. Journal of the Philosophy of History 2: 83104.

Tomasello M and Moll H (2010) The gap is social: human shared intentionality and culture, in P M Kappeler and J B Silk (eds) Mind the Gap. Berlin: Springer-Verlag: 331-349. 
Trapeze Collective (2008) The rocky road to a real transition. The Commoner 13: 141-167.

Tronto J C (2009) Moral Boundaries: A Political Argument for an Ethic of Care. New York: Routledge.

Tuan YF (1974) Space and place: humanistic perspective. Progress in Geography 6(21): 1-52.

Tuomela R (2005) We-intentions revisited. Philosophical Studies 125(3): 327-369.

Tuomela R (2007) The Philosophy of Sociality: The Shared Point of View. Oxford: Oxford University Press.

Vasudeven A (2014) The makeshift city: towards a global geography of squatting. Progress in Human Geography. Online first: DOI: 10.1177/030913251431471.

Wellman B (1999) Networks in a Global Village. Life in Contemporary Community. Boulder, CO.: Westview Press.

Williams J (2008) Predicting an American future for cohousing Futures 40: 268-286.

Wills J (2012) The geography of community and political organisation in London today. Political Geography 31: 114-126

Wolch J (2007) Green urban worlds. Annals of the Association of American Geographers 97(2): 373-384.

Zammit M (2017) The Long Shadow Thrown over the Actions of Men. Pedagogy, Politics and Philosophy of Peace: Interrogating Peace and Peacemaking, 181.

Zeng M (2014) Subaltern cosmopolitanism: concept and approaches. The Sociological Review 62: 137-148. 